\title{
INTEROPERABILITAS SISTEM TERDISTRIBUSI BERBASIS PROTOKOL SOAP
}

\author{
Mohamad Ali Wardana ${ }^{1}$, Rahman ${ }^{2}$ \\ 1aliwardana99@gmail.com, ${ }^{2}$ rahman87@gmail.com \\ ${ }^{1}$ Staf Pengajar STMIK Lamappapoleonro Soppeng, ${ }^{2}$ Staf Pengajar UIN Alauddin Makassar
}

\begin{abstract}
Abstrak
Sistem e-KTP yang yang diadopsi pemerintah menerapkan sistem database nasional kependudukan terpusat. Database ini menjadi referensi resmi dan yang dipercaya untuk mengidentifikasi status dan informasi kewarganegaraan seseorang. Siapapun baik perseorangan maupun lembaga dapat menjadikan referensi database nasional untuk memproses data kependudukan seseorang melalui sistem perangkat lunak kantor, lembaga atau struktur pemerintahan lokal di Indonesia. Kehadiran teknologi sistem terdistribusi dengan jenis arsitektur berbasis protokol SOAP, memungkinkan komunikasi perangkat lunak lintas platform sistem operasi dan bahasa pemrograman, berkomunikasi dengan model database apapun yang menyediakan antarmuka aplikasi layanan web. Penelitian ini telah menguji arsitektur SOAP untuk mengakses struktur data kependudukan dengan menggunakan perangkat lunak lintas bahasa pemrograman (Java dan Visual Basic .Net 2008). Pengujian menunjukan kinerja yang dapat diandalkan dengan tingkat akurasi data perolehan dan validasi record penduduk $100 \%$. Hasil lainnya yang berjalan baik adalah pada pengujian Cross Tringgering-Event dan Penanganan struktur data server pada sisi oleh client. Meskipun demikian fleksibelitas penggunaan tipe data kompleks dan kecepatan respon server kurang begitu baik.
\end{abstract}

Kata Kunci: SOAP, e-KTP.

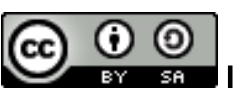

\section{Pendahuluan}

Masalah kependudukan yang sering terjadi telah menjadi dasar yang kuat untuk menerapkan sistem kependudukan dengan pendataan elektronik. Beragam masalah kependudukan seperti bayankanya warga negara miskin yang tidak menerima Bantuan Langsung Tunai (BLT) karena tidak terdata dengan baik dalam data kependudukan adalah salah satu contohnya. Kasus lainnya diantaranya sulitnya warga negara akibat adanya konsep pemegang KTP Nasional dan KTP Daerah, menjadikan warga terkadang nekad menggunakan KTP ganda. Olehnya penerapan e-KTP diharapkan menjadi solusi dengan menerapkan sistem database nasional kependudukan untuk setiap warga negara.

Database nasional adalah database yang harus menjadi referensi tunggal tentang validasi dan informasi kewarganegaraan seorang di republik ini. Untuk menjaga konsistensi data, maka database ini dirancang terpusat untuk menghindari duplikasi data kependudukan. Berbagai instansi pemerintahan, struktur pemerintahan kota hingga ke desa, lembaga-lembaga non pemerintahan harus menggunakan referensi database nasional demi validitas dan legalitas informasi kependudukan untuk suatu keperluan yang menggunakan data-data kependudukan secara massif.

Kehadiran sistem terdistribusi dengan protokol SOAP, memungkinkan suatu lembaga maupun perseorangan (dengan ijin akses tertentu) me-request informasi dai database nasional melalui komunikasi antar program tanpa melibatkan persona petugas administrasi. Komunikasi antara program atau modul program ini akan berlangsung efektif dalam memberikan informasi dan validasi kewarganegaraan dibanding dengan prosedur manual melibatkan petugas administrasi. Modul program pun dapat menjalankan proses tanpa harus melibatkan manusia setelah mendapatkan informasi via komunikasi dengan server database nasional.

Tujuan dan manfaat yang dapat diperoleh dari penelitian ini:

1. Merancang sebuah usulan sistem terdistribusi berbasis protokol SOAP untuk menangani komunikasi perangkat lunak lintas platform dalam mempertukaran struktur data kependudukan.

2. Menguji kinerja protokol SOAP dalam arsitektur interoperabilitas sistem terdistribusi dalam menangani struktur data, memicu event lintas platform dan kecepatan komunikasi data dan informasi dengan tetap mempertahankan kosistensi struktur data bawaannya. 
Adapun batasan penelitian ini adalah:

1. Skenario yang dikembangkan adalah proses komunikasi suatu aplikasi client berbasis VB .Net dengan server berbasis Java yang dikembangkan dengan Netbeans IDE.

2. Skenario hanya menunjukan proses permintaan informasi kependudukan dan proses penambahan record penduduk kedatabase server serta proses validasi status registrasi seseorang berdasarakan NIK tertentu. Skenario tidak menerapkan proses validasi pengguna dan level-level akses yang harus dimiliki communicator-clientuntuk mengeksekusi layanan tertentu.

3. Pengujian juga tidak menerapkan salah satu bentuk enkripsi dalam mengamankan pesan XML-SOAP untuk proses request maupun response. Sehingga seluruh pengujian kecepatan, konsistensi layanan dan kinerja umum perangkat lunak adalah tanpa perhitungan terhadap proses kompresi dan dekompresi pesan SOAP sebagaimana layaknya keamanan protokol berbasis plainteks pada umumnya.

\section{Landasan Teori}

\subsection{Elektronik KTP}

e-KTP atau KTP Elektronik adalah dokumen kependudukan yang memuat sistem keamanan / pengendalian baik dari sisi administrasi ataupun teknologi informasi dengan berbasis pada database kependudukan nasional.Penduduk hanya diperbolehkan memiliki 1 (satu) KTP yang tercantum Nomor Induk Kependudukan (NIK). NIK merupakan identitas tunggal setiap penduduk dan berlaku seumur hidup.[1]

Nomor NIK yang ada di e-KTP nantinya akan dijadikan dasar dalam penerbitan Paspor, Surat Izin Mengemudi (SIM), Nomor Pokok Wajib Pajak (NPWP), Polis Asuransi, Sertifikat atas Hak Tanah dan penerbitan dokumen identitas lainnya (Pasal 13 UU No. 23 Tahun 2006 tentang Adminduk)

\subsection{Sistem Terdistribusi}

Sistem terdistibusi merupakan sebuah sistem yang komponennya berada pada jaringan komputer. Komponen tersebut saling berkomunikasi dan melakukan koordinasi hanya dengan pengiriman pesan (message passing).Dengan kata lain sistem ini melibatkan lebih dari satu komputer dalam suatu infrastruktur jaringan baik local,internet bahkan wireless. Sebuah sistem terdistribusi, tidak hanya melakukan komunikasi antara satu proses pada satu komputer dengan proses pada komputer yang lain, namun juga perlu mempertimbangkan ketersediaan infrastruktur jaringan yang memadai dan juga dukungan standarisasi sistem yang terbuka [2].

Dewasa ini implementasi sistem terdistribusi merujuk kepada tiga teknologi utama komputasi dan sistem terdistribusi yaitu Remote Method invocation (RM-Java), Common Object Request Broker Architecture (CORBA) dan Web Service bebasis Simple Object Access Protocol (SOAP). Protokol SOAP adalah model yang paling mudah diterapkan untuk mendukung interoperabilitas sistem terdistribusi. Ini karena SOAP adalah protokol berbasis XML (eXtensible Markup Language) dan HTTP (HyperText markup Language) yang familiar dan dan mudah dikodekan.

Suatu sistem teristribusi adalah suatu sistem yang berjalan diatas protokol TCP/IP dengan mengandalkan keterhubungan melalui jaringan komputer. Oleh karena itu ketersediaan sumber daya jaringan dan konektivitas menjadi hal kunci yang mendukung kinerja sistem model terdistribusi.

2.3. Interoperabilitas Perangkat Lunak

Interoperabilitas perangkat lunak secara sederhana dapat dinyatakan sebagai kerjasama antara dua atau lebih perogram aplikasi yaitu perangkat lunak yang berrbeda platform sistem operasi dan bahasa pemrograman dalam menghitung atau mengolah data tertentu. Interoperabilitas itu bisa terjadi antara sebuah perangkat lunak yang ditulis dalam bahasa pemrograman Delphi dan dijalankan di atas sistem operasi Microsoft Windows dengan perangkat lunak lain yang berjalan di atas sistem operasi Linux dan ditulis dalam bahasa pemrograman Java [3.]

Isu tentang interoperabilitas antara perangkat lunak menjadi isu yang menarik dan penting mengingat kebutuhan akan pertukaran data dan infomasi yang semakin besar, beragam dan meningkat intensitasnya. Sementara disisi lain masing-masing pengguna menggunakan sistem operasi, perangkat lunak yang berbeda-beda atas alasannya masing-masing.

Selain itu kehadiran berbagai macam vendor yang berbeda dan penciptaan bahasa pemrograman yang semakin banyak akan menciptakan kesenjangan yang semakin jauh antara proses-proses terhadap informasi dan data. Hal ini akan memberi dampak ekonomis biaya tinggi terhadap data dari sisi konversi data semata jika tidak ditangani melalui suatu standar yang menjadi acuan dalam 
ILKOM Jurnal Ilmiah Volume 8 Nomor 1 (April 2016)

kompatibilitas proses perangkat lunak. Interoperabilitas perangkat lunak saat ini digagas dalam dua pendekatan penting. Kedua pendekatan tersebut adalah interoperabilitas proses perangkat lunak dan Kompatibilitas semantik data yang diproses atau dipertukarkan. Model XML dalam protokol SOAP adalah salah satu pendekatan untuk membangun arsitektur sistem yang mendukung model interoperabilitas antar perangkat lunak. SOAP message yang dikirim oleh aplikasi.

\subsection{Protokol SOAP dan HTTP}

Simple Object Access Protocol (SOAP) adalah sebuah protokol komunikasi berbasis XMLPlaintext. Pesan SOAP adalah sebuah plain teks biasa yang ditulis menurut struktur eXtenxible Markup language (XML) dan dipertukarkan antar perangkat lunak melalui protokol komunikasi lain, misalnya protokol HyperText Markup Language (HTTP protocol) [4].

Sebuah struktur XML sebagai pesan SOAP adalah struktur XML dengan tag-tag standar meskipun XML tidak didesain dengan tag-tag definitif. Gambar berikut memperlihatkan sebuah struktur pesan SOAP. Hyper Text Transfer Protocol (HTTP) adalah protokol transfer data (byte stream) berbasis plaintext untuk mentransmisikan konten suatu website. HTTP dikenal aman karena tidak melewatkan perintah eksekusi seperti halnya protokol komunikasi lainnya.HTTP ini sebagaimana umumnya bekerja sebagai protokol web sehingga dikenal sebagai Web Proocol. HTTP secara standar bekerja pada nomor port 80 baik dalam me-request data maupun dalam melakukan POST. Protokol HTTP dalam arsitektur sistem terdistribusi berperan menjadi protokol pembawa pesan SOAP yaitu struktur XML. Suatu teks header dari protokol HTTP akan ditambahkan pada suatu pesan SOAP sebagai pembawa struktur XML tersebut.

\subsection{Binding Process}

Dalam aplikasinya, Toko utama digambarkan sebagai pemasok/server yang berhubungan dengan reseller /client dimana beberapa reseller/client menggunakan OS yang berbeda (beragam platform) yang berfungsi memberikan informasi berupa update harga buku terbaru, barang yang tersedia, barang yang laris, barang yang kurang peminatnya, sisa stok dan berbagai info lainnya yang kemudian dapat mendistribusikan informasi tersebut ketoko utama sebagai server, jadi apabila ada reseller/client yang inginmencari data buku terbaru, client tinggal mengakses data yang terdapat di toko buku utama kemudian dari data base toko utama akan mengirim informasi yang diminta melalui SOAP yang terdapat pada apikasi client. Pada bagian ini akan ditunjukan proses komunikasi yang terjadi antara aplikasi melalui pertukaran pesan plain-SOAP (pesan SOAP murni). Pada bagian ini sengaja diperlihatkan tanpa melakukan parsing terhadap pesan XML semata-mata ingin menunjukan proses yang sesungguhnya terjadi antara aplikasi yang berkomunikasi dengan berbasis protocol SOAP [5].

\section{Metode}

\subsection{Model Arsitektur e-KTP}

Sebuah database nasional yang menjadi referensi tunggal data kependudukan menjadi tulang punggung sistem ketersediaan data dan informasi kependudukan. Database dirancang dengan sistem replika database untuk tujuan keamanan dan konsistensi data. Selain itu model replika memungkinkan layanan tetap tersedia dalam kondisi sebuah komputer server bermasalah.

Server database menyediakan interface langsung untuk tujuan administrasi database. Pengaksesan langsung tersebut haruslah merupakan administrator sistem dan memiliki kewenangan untuk itu. Pada level ini proses dan akses ke server tanpa perantaraan protokol SOAP.

Sisi klien adalah keseluruhan institusi pemerintahan, struktur pemerintahan, lembagalembaga baik pemerintah maupun non pemerintah yang diberi kewenangan untuk melakukan akses terhadap sistem database nasinal. Setiap klien akan memiliki account dan mengalami verifikasi saat melakukan koneksi. Setiap verifikasi akan menentukan level akses terhadap database yang berhak dilakukan oleh klien. Hal ini karena tidak semua klien memiliki kepentingan dan olehnya memiliki hak mengakses sebebas-bebasnya rahasia negara.

Setiap instansi, lembaga atau klien individu, sebagaimana nampak pada gambar, diasumsikan memiliki sistem operasi dan perangkat lunak beragam. Keragaman ini akan ditangani melalui arsitektur sistem dan tidak akan menimbulkan masalah dalam komunikasi perangkat lunak. 
ILKOM Jurnal Ilmiah Volume 8 Nomor 1 (April 2016)

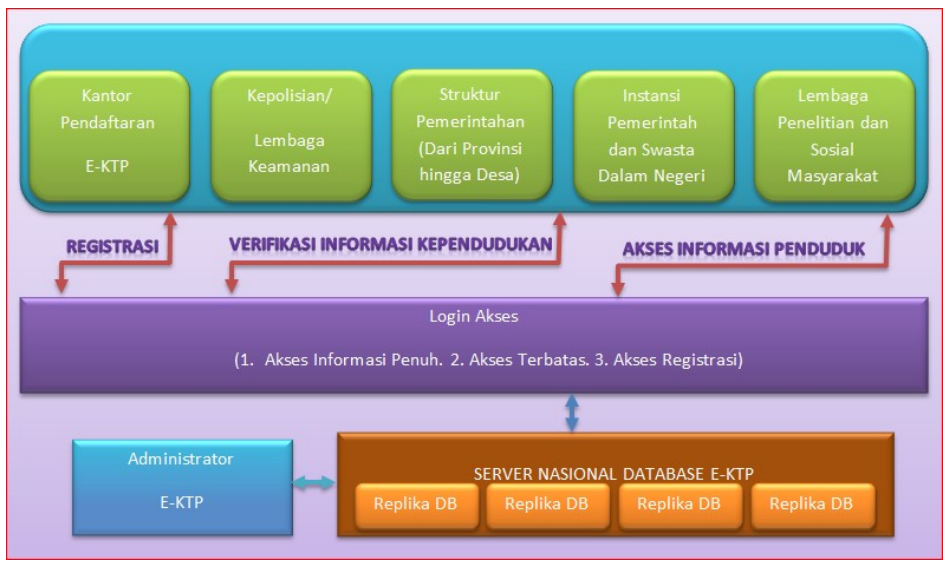

Gambar 1. Model Arsitektur e-KTP

\subsection{Model Sistem Perangkat Lunak}

Sistem database nasional terpusat adalah sebuah sistem yang berdiri sendiri dan dapat beroperasi tanpa model distribusi sistem. Olehnya untuk memberi layanan kepada program klien, sistem menerapkan antarmuka Web Application sebagai lapisan interaksi sistem dengan klien. Lapisan WebApp selain menangani pesan SOAP juga dirancang melakukan fungsi validasiterhadap setiap klien yang melakukan koneksi.

Sisi klien terinstalasi pada lingkungan sistem operasi berbeda-beda. Demikian juga klient adalah program yang ditulis dalam bahasa pemrograman berbeda-beda. Untuk membanguun komunikasi dengan server, klien akan menggunakan pesan SOAP. Pesan SOAP ini adalah binding antara HTTP dan XML. Berdasarkan pesan tersebut, server akan mengirimkan SOAP Responseyang juga merupakan binding HTTP dan XML.

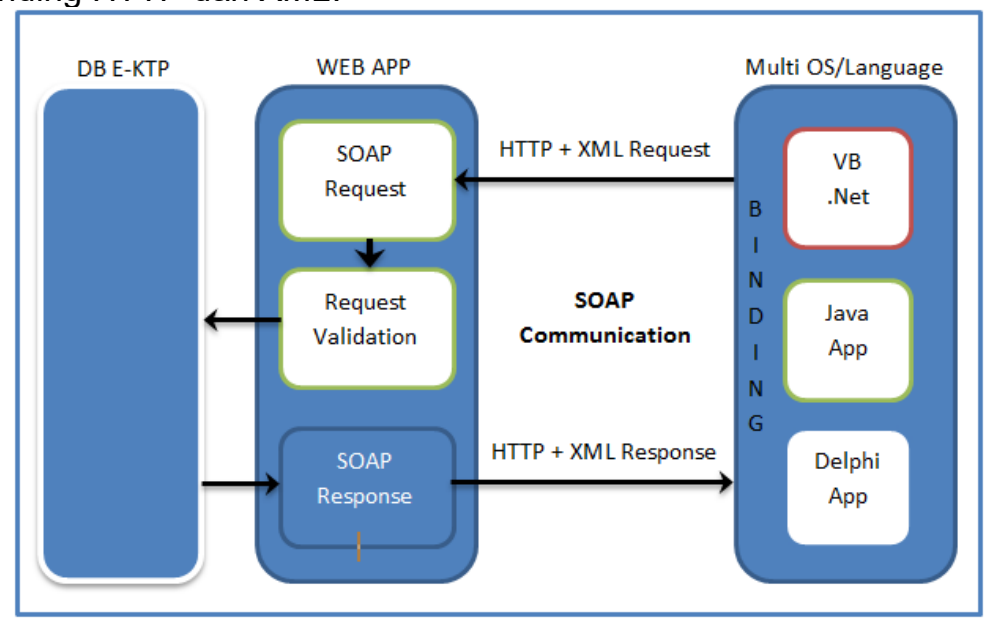

Gambar 2. Model Sistem Perangkat Lunak

\section{Hasil}

Perancangan sistem menggunakan suatu model database disimulasikan untuk menyimpan data terstruktur. Untuk mengakses database dan struktur data, model lapisan (layer) antarmuka berbasis aplikasi web untuk keperluan interaksi tersebut diterapkan. Web service dapat dengan baik mengakses struktur data tersimpan dan memodelkannya dalam instansi obyek kelas-kelas java. Setiap struktur data yang direpresentasikan dalam struktur kelas-kelas java diakses dengan properti setter dan getter.

Proses kompilasi kelas-kelas java untuk memodelkan struktur data database berjalan baik demikian juga proses deployweb service dapat dilakukan dengan mudah tanpa masalah kompatibilitas perangkat lunak.Kendala muncul ketika antarmuka server dibangun untuk mengkomunikasikan tipe data kompleks kepada klien. Hal ini karena web service tidak mendukung mendeploy tipe data kompleks sebagai obyek kembalian proses. Namun secara umum implementasi antarmuka komunikasi klien pada sisi server berjalan baik dan cukup mudah dilakukan. 
ILKOM Jurnal Ilmiah Volume 8 Nomor 1 (April 2016)

Untuk mengakses server, klien berbasis Net framework yang ditulis dengan bahasa pemrograman Visual basic .Net 2008 dipersiapkan dengan tiga fungsi utama, yaitu Registrasi, Verifikasi kependudukan dan Menarik informasi dari server.

Untuk menangani struktur data hasil proses dari server, struktur obyek (kelas obyek) Visual Basic memberi dukungan dan tingkat implementasi yang mudah. Visual Basic dengan Netframework menyediakan tingkat interoperabilitas yang tinggi terhadap komunikasi XML. Setiap antarmuka getter dan setter yang diimplementasikan pada sisi server dapat diakses dengan mudah melalui obyek library yang digenerate melalui WSDL (Web Service description Language) server. Netframework memberikan akses langsung terhadap fungsi-fungsi operasi web service melalui library tersebut secara fleksibel layaknya mengakses obyek lokal.

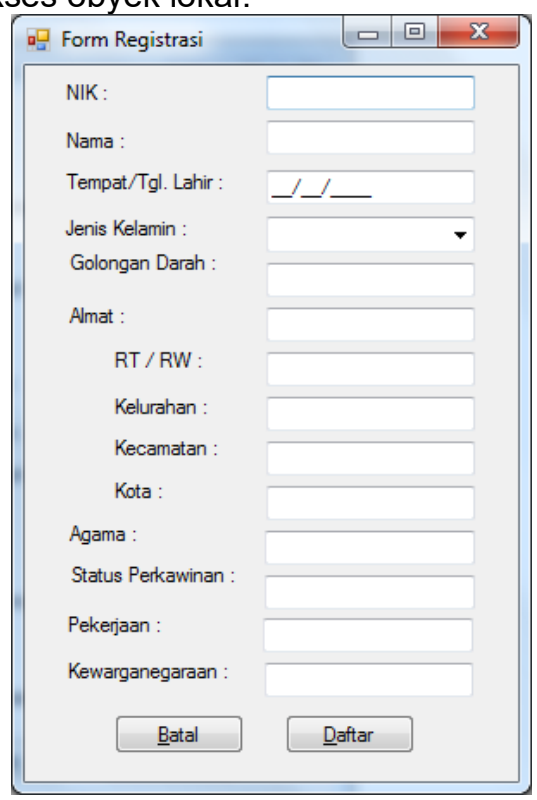

Gambar 3. Form Registrasi

Pengujian pemicuan event untuk menjalankan operasi pada sisi server berjalan baik. Demikian juga operasi-operasi lokal terpicu dengan baik melalui rangkaian Cross Tringgering-Event. Hasil operasi server memberi respon kembalian yang akurat $100 \%$ pada sisi klien sesuai dengan kevalidan data server.

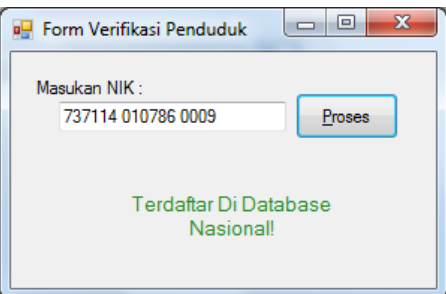

Gambar 4. Form Verifikasi Penduduk

Proses penarikan informasi berdasarkan struktur data server dilakukan untuk setiap field data dari sisi klien. Ini karena masalah kompatibilitas tipe data yang tidak cukup baik dideploy pada sisi server. Dengan demikian tidak mampu mengkomunikasikan semantik obyek secara langsung.

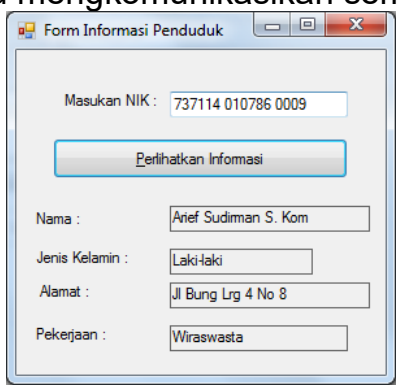


ILKOM Jurnal Ilmiah Volume 8 Nomor 1 (April 2016)

Gambar 5. Form Informasi Penduduk

Interoperabilitas tidak menunjukan performansi yang cukup baik dalam hal kecepatan. Proses penarikan data dari server berlangsung lambat. Secara lengkap hasil bisa dilihat pada tabel dibawah.

Tabel1. Hasil pengujian

\begin{tabular}{|c|c|c|c|}
\hline No & Item Uji & Server:(Java Netbeans IDE) & Client : VB .Net \\
\hline 1. & $\begin{array}{l}\text { Penanganan } \\
\text { Event dari suatu proses }\end{array}$ & Berjalan Baik & Berjalan Baik \\
\hline 2. & Cross Tringgering-Event & Berjalan baik & Tidak diterapkan pada sisi client \\
\hline 3. & $\begin{array}{l}\text { Penanganan Keterhubungan } \\
\text { struktur data antar aplikasi }\end{array}$ & $\begin{array}{l}\text { Tidak diterapkan pada sisi } \\
\text { server }\end{array}$ & $\begin{array}{l}\text { Berjalan baik (Client menangani } \\
\text { dengan baik struktur data kiriman } \\
\text { server) }\end{array}$ \\
\hline 4. & $\begin{array}{l}\text { Fleksibilitas Penggunaan Tipe } \\
\text { Data Kompleks }\end{array}$ & Kurang Baik & Kurang Baik \\
\hline 5. & Kecepatan Respon Server & $\begin{array}{l}\text { Lambat (khususnya ketika } \\
\text { merequest data yang besar) }\end{array}$ & - \\
\hline 6. & $\begin{array}{l}\text { Akurasi data dan validasi } \\
\text { record penduduk }\end{array}$ & - & $\begin{array}{l}100 \% \text { (sama persis dengan yang } \\
\text { berada pada server) }\end{array}$ \\
\hline
\end{tabular}

\section{Kesimpulan Dan Saran}

\subsection{Kesimpulan}

Sistem terdistribusi berbasis protokol SOAP adalah salah satu alternatif yang handal dalam membangun sistem yang mengutamakan validitas data yang dikomunikasikan dalam lingkungan jaringan yang berbeda secara ekstrim. Sistem berbasis protokol SOAP bersifat plain teks sehingga tetap memberi dukungan interoperabilitas dalam jaringan intranet yang relatif lebih aman.

\subsection{Saran}

Penelitian dan pengembangan lebih lanjut interoperabilitas berbasis protokol SOAP perlu dilakukan dibidang parsing XML untuk meningkatkan kecepatan serta implementasi algoritma yang tepat untuk mendukung keamanan komunikasi. Perlu adanya model dan representasi yang mudah untuk diimplementasikan model obyek kompleks dalam pesan SOAP sehingga obyek-obyek program mudah dikomunikasikan melalui protokol ini.

\section{Daftar Pustaka}

[1] Haq Saiful dkk. 2014. Public Service Quality in Making E-KTP (Electronic Citizen ID) in District of Suboh Situbondo Regency. Artikel Ilmiah Hasil Penelitian Mahasiswa 2014. Jember .

[2] Hidayanto Nur Adi dkk. 2015. Sistem Terdistribusi Untuk Sistem Informasi Administrasi Kependudukan Dengan Web Service. Jurusan Teknik Informatika Sekolah Tinggi Manajemen Informatika dan Komputer Teknokrat Lampung.

[3] Rosmi Yani Amran. 2007. Interoperabilitas Sistem KTP Elektronik Terdistribusi Berbasis Simple Object Access Protocol (SOAP). Jurnal Fakultas IImu Komputer, Program Studi Teknik Informatika, Universitas Muslim Indonesia, Makassar.

[4] Gottschalk, K. 2002. Introduction to Web services architecture. [Online] tersedia: http:// www.research. ibm.com/journal/sj/412/gotts chalk.pdf.

[5] Maulidya. 2004. Analisis Aplikasi Web Service Validasi Kartu Kredit. Thesis S2. Program Studi IImu Komputer UGM Yogyakarta. 